\title{
Libros hospitalarios sevillanos en la Edad Moderna
}

\author{
Pablo Alberto MESTRE NAVAS \\ (Universidad de Sevilla)
}

\section{Resumen}

Durante la Edad Moderna muchos de los hospitales sevillanos vivieron una etapa de esplendor, transformándose en centros en los que el libro jugó un papel esencial. Los establecimientos de caridad requirieron una tipología libraria muy concreta, tanto para atender sus necesidades sanitarias, en las que médicos y boticarios se presentan como creadores y consumidores de libros de temática afín a sus disciplinas de conocimiento, como libros destinados a otras funcionalidades y actividades que se desarrollaban en el entorno hospitallario, fundamentalmente libros orientados al servicio litúrgico y al gobierno del centro. El presente artículo pone manifiesto la actividad libraria de algunos hospitales sevillanos durante la Edad Moderna, así como la participación de algunos libreros del momento en su producción, analizándose las particularidades y características de algunos de los manuscritos más representativos.

Palabras clave: Libros hospitalarios. Biblioteca del Pozo Santo. Libreros sevillanos. Libro de oraciones del Hospital de San Lázaro. Hospitales. Sevilla.

\section{Hospital Books from Seville During the Modern Age}

\section{Abstract}

During the Modern Age at Seville, many hospitals lived a period of splendor, which became centreswhere books had an essential role. Charity establishments required a very specific book typology: (a) to meet their health necessities, in which physicians and pharmacists were presented as creators and consumers of books related to their subject knowledge disciplines, and (b) as books intended for other functions and activities in the hospitals, especially as both liturgical and government books. This article claims how hospitals' 
librarian activities from Seville's Modern Age were. As well as the participation of some booksellers production time and the analysis of the peculiarities and characteristics of some of the most representative manuscripts of this age

Keywords: Hospital books. Pozo Santo Library. Sevilla's Booksellers. Prayer books from San Lazaro Hospital. Hospitals. Seville

\section{Introducción: el fenómeno hospitalario en Sevilla}

Desde tiempos medievales el fenómeno hospitalario adquirió gran auge en la ciudad del Betis. Su presencia fue inmediata a la llegada de los ejércitos castellanos, comandados por el santo rey Fernando III, en los momentos previos a la toma de la ciudad, hecho que se produciría en 1248. En este sentido, los primeros cronistas de Sevilla ya adjudicaron a este soberano el protagonismo de una de las fundaciones más emblemáticas, como fue la de la Real Casa de San Lázaro, establecimiento dedicado a los malatos o leprosos y que estuvo ubicado a las afueras de la urbe, ${ }^{1}$ junto a una torre labrada por dos célebres moros, los Gausines, sobre cimientos romanos. ${ }^{2}$ No parece ser el único de los hospitales asociados a la figura del Rey Santo, ya que hay autores que no dudan en aseverar que a él se debió uno de los primeros establecimientos que existieron en la ciudad y que estuvo vinculado, con posterioridad, al gremio de los calafates, cuyos orígenes se contextualizan en el marinero barrio de Triana y que habría sido fundado para prestar servicios a los soldados enfermos o heridos. ${ }^{3}$

Sea como fuere, lo que sí resulta evidente es que todo apunta a que la presencia hospitalaria en Sevilla fue abundante; el cronista Alonso Morgado, en 1587, ${ }^{4}$ llegó a afirmar que durante la Edad Media existió un hospital en

\footnotetext{
${ }^{1}$ La erección de este establecimiento sanitario fue, posiblemente, inmediato a la conquista de Sevilla; todo apunta a que, entre las huestes castellanas que acompañaron a Fernando III y que estaban dispuestas alrededor de la ciudad participando del asedio, se detectaron algunos casos de lepra. Por este motivo, se aconsejó su aislamiento en un núcleo habitacional alejado de la ciudad para impedir el contagio (Francisco ColLANTES DE Terán-CaAmaño, Los establecimientos de caridad de Sevilla, Sevilla, Ayuntamiento de Sevilla, 2009, pp. 11-12).

2 Felipe MARTíneZ PÉREZ, «La medicina sevillana en el siglo XIII y especialmente en la época de la conquista de Sevilla», Archivo Hispalense, 12, 39-40 (1956), p. 145.

3 Fernando Chueca Goitia [et al.], Los hospitales de Sevilla, Sevilla, Real Academia de Buenas Letras, 1989, p. 40.

${ }_{4}^{4}$ Alonso Morgado, Historia de Sevilla, en la qual se continen sus antigüedades, grandezas, y cosas memorables en ella acontecidas, desde su fundación hasta nuestros tiempos, Sevilla, Imprenta de Andrea Pescioni y Iuan León, 1587, p. 22.
}

Titivillus, ISSN 2387-0915, ISSN-e 2603-9966, 2 (2016), pp. 157-178 
cada una de las distintas collaciones. De esta forma, en Sevilla, la ciudad que más tenía de toda la Corona de Castilla, ${ }^{5}$ ya existirían numerosos hospitales durante ese periodo, número que se disparó en la Edad Moderna, con ocasión de la transformación de la ciudad en el puerto privilegiado para el tráfico con las Indias.

La multiplicidad de hospitales, muchos de ellos fundados por gremios y hermandades y carentes de un patrimonio capaz de mantener la actividad sanitaria, bajo cuyas premisas nacieron, provocó que, muy pronto, existiesen intentos por reducir su número y aplicar sus escasas rentas e institutos a otros establecimientos más consagrados y cuya actividad estaba fuera de dudas; así ya, el arzobispo Diego Hurtado de Mendoza y Quiñones, dio buena cuenta de la inutilidad de algunos de ellos, razón por la que no dudó en comenzar un proceso de reducción hospitalaria en 1488 cuando obtuvo, del papa Inocencio VIII, la bula pertinente, contando con la aquiescencia de los Reyes Católicos. ${ }^{6}$ Sin embargo, la fuerte y efectiva oposición que organizaron, tanto las hermandades que sustentaban la hospitalidad como el Cabildo de Sevilla, impidieron que el proceso se llevase a efecto. Habría que esperar algunos años para que la idea fuese retomada por el cardenal Rodrigo de Castro Osorio en el último tercio del siglo XVI, quien, con el incondicional apoyo de Felipe II, logró reducirlos definitivamente, no sin menoscabo de provocar en la población innumerables quejas y malestar como otrora sucediese. El largo proceso de la reducción trajo como principal consecuencia la supresión de setenta y cuatro hospitales, destinándose su patrimonio y rentas a dos: el del Amor de Dios, que ya existía y del que se desconoce su fecha fundacional, ${ }^{7}$ y el del Espíritu Santo, de nueva creación.

Con todo, siguieron existiendo algunos hospitales de origen medieval porque sus rentas y actividad permitían el sostenimiento de la obra pía. Algunos de los más importantes y célebres estuvieron bajo el real patrocinio, como el de San Lázaro, el Hospital Real o de Nuestra Señora del Pilar, o el de los Inocentes, llamado también de San Cosme y San Damián. Otros, como el de las Bubas, estuvieron bajo amparo del Cabildo de Sevilla, mientras que otros importantes establecimientos fueron de fundación personal, como el de

\footnotetext{
5 En efecto, como apuntó Miguel Ángel Ladero Quesada, las collaciones quedaron establecidas hacia 1250 sobre solares o edificios que habían pertenecido a primitivas mezquitas, contabilizándose hasta veinticuatro. A fines del siglo XIII se añadió la collación de Santa Ana, en el arrabal de Triana, y, después de 1391, tres más que estaban dentro del recinto amurallado que conformaba la judería: Santa María la Blanca, Santa Cruz y San Bartolomé Nuevo (Miguel Ángel Ladero Quesada, Historia de Sevilla. La ciudad medieval, Sevilla, Universidad de Sevilla, 1989, p. 200).

${ }^{6}$ Juan Ignacio Carmona García, El sistema de hospitalidad pública en la Sevilla del Antiguo Régimen, Sevilla, Diputación Provincial de Sevilla, 1979, pp. 178-179.

${ }^{7}$ M Teresa López DíAz, Estudio histórico-farmacéutico del Hospital del Amor de Dios, Sevilla, Diputación Provincial de Sevilla, 1978, p. 41.
} 
San Hermenegildo, erigido a instancias del cardenal Juan de Cervantes y Bocanegra el 16 de noviembre de 1453, por una de sus cláusulas testamentarias suscritas ante el notario Pedro Martínez de la Palma, ${ }^{8}$ y el de las Cinco Llagas, fundado por la piedad de la excelente señora Catalina de Ribera en 1503, y bajo jurisdicción pontificia por concesión de la bula otorgada por el papa Alejando VI, el 13 de marzo de 1500. ${ }^{9}$ Finalmente, subsistieron otros hospitales que permanecieron bajo el gobierno de hermandades y cofradías, como el de la Santa Caridad y el de la Misericordia, este último consagrado a sufragar las dotes de doncellas, y otros que fueron fundados con posterioridad a la reducción del siglo XVI.

Los hospitales que continuaron su labor asistencial, después de la reducción emprendida por el cardenal Rodrigo de Castro, eran centros consolidados, dotados por innumerables rentas y propiedades, fruto de donaciones y disposiciones testamentarias. La mayoría de ellos contaron con sistemas complejos de gobierno y administración, estando bajo la supervisión de autoridades civiles y religiosas, que velaban por el fiel cumplimiento de sus institutos piadoso, así como por la estricta observancia de sus constituciones, reglas y ordenanzas.

\section{El mundo del libro en la hospitalidad sevillana}

Libros para uso litúrgico

El mundo del libro en la hospitalidad sevillana debe contextualizarse en las diferentes funciones y aspectos que dichas instituciones desarrollaron durante el Antiguo Régimen. Por este motivo, lo primero que debe entenderse para comprender la realidad libraria de los establecimientos de caridad es que los hospitales, antes que otra cosa, eran centros en los que se realizaban ceremonias religiosas, pudiendo estar bajo la administración y gobierno de alguna comunidad que atendiera el culto divino. Por otra parte, es obvio que, tradicionalmente, la supervisión de estos centros corría bajo la responsabilidad del prelado de la diócesis, quien, por lo general, solía enviar visitadores que garantizaban el funcionamiento del establecimiento. Desde esta perspectiva, hay que subrayar que la Medicina, como ciencia y disciplina, corrió pareja a las prácticas devotas y piadosas que se circunscribían dentro de la órbita eclesiástica, de forma que la sanación del cuerpo implicaba la previa sanación y corrección del alma. No es extraño encontrar alusiones a esta realidad en las

8 Archivo de la Diputación Provincial de Sevilla (ADPSE). Hospital del Cardenal, Sec. Fundación y gobierno, leg. 1 A, s.f.

9 Diego OrTIZ De ZÚÑIgA, Annales eclesiásticos de la muy noble, y muy leal, civdad de Sevilla, metrópoli de la Andaluría, que contienen sus más principales memorias, Sevilla, Imprenta Real, 1677, p. 417.

Titivillus, ISSN 2387-0915, ISSN-e 2603-9966, 2 (2016), pp. 157-178 
diferentes compilaciones jurídicas medievales y modernas; así, Las Siete Partidas, ordenadas por Alfonso X el Sabio (Part. I, tit. IV, ley XXXVII), ya establecían la preceptiva confesión del paciente antes de recibir la visita del físico, primándose el alma al cuerpo - «pensar deue el ome primeramente del alma, que del cuerpo: porque es más noble e más preciada»—.

En este sentido, los hospitales debían ser centros no solo para el tratamiento paliativo de las enfermedades o dolencias, sino lugares en los que se preparaba al paciente a bien morir. Aquí hay que encontrar la razón por la que en las primitivas constituciones de 1503 del Hospital de las Cinco Llagas de Sevilla se reglamentase, en su tercer artículo, que los clérigos encargados de la visitación de las enfermas realizasen lecturas provechosas para el alma, señalándose como libro idóneo para ello el Arte de bien morir, ${ }^{10}$ pudiéndose compaginar con lecturas hagiográficas que el sacerdote llevase consigo durante la visita, quedando siempre a su discreción.

Como lugares en los que se realizaban prácticas devotas, los hospitales, durante el Antiguo Régimen, no solo se habían fundado bajo una advocación religiosa, sino que solían contar, por lo general, con algún oratorio o iglesia en la que se hacían las ceremonias litúrgicas acostumbradas, por lo que debían de tener libros propios y análogos a los de otros templos. De ahí, que fuese habitual encontrar entre sus fondos bibliográficos libros litúrgicos destinados al servicio de altar y oficios divinos. A ellos, hay que sumar aquellos destinados a la administración de los sacramentos o los de uso interno, en los que el clero anotaba todo lo concerniente a la liturgia. Las fuentes documentales que se conservan en el Archivo de la Diputación Provincial de Sevilla permiten conocer de primera mano el encargo de algunos libros de esta tipología, especialmente durante la Edad Moderna, especificándose el nombre de los libreros y los gastos que ocasionaron su producción. Sin duda, los datos más interesantes se encuentran en el de las Cinco Llagas, hospital que, por sus dimensiones y patrimonio económico, fue uno de los principales de Sevilla hasta bien entrada la Edad Contemporánea. El establecimiento que fundara Catalina de Ribera, y al que dejara parte de su cuantioso patrimonio su hijo, Fadrique Enríquez de Ribera, I marqués de Tarifa, tenía una de las iglesias más suntuosas de la capital andaluza. Félix González de León, a mediados del siglo XIX, no dudaba en afirmar que, tras la Iglesia Catedral, el templo de las Cinco Llagas era el más imponente - «está la iglesia que es una de las mejores, sino es la segunda de Sevilla»-. ${ }^{11}$ Necesitó por ello libros con los que atender estas

\footnotetext{
10 Posiblemente se tratase de la versión castellana del Ars moriendi, impreso en Zaragoza a fines del siglo XV, ya que el Espejo y Arte muy brene y prouechoso para ayudar a bien morir en el incierto dia y hora de la muerte del carmelita Jaime Montañés es de fecha posterior a la de la aprobación de las primeras constituciones del hospital (ADPSE. Hospital de las Cinco Llagas, Sec. Fundación y gobierno, leg. 1, exp. 3, f. 23).

11 Félix GONZÁlez de LEÓN, Noticia artística histórica y curiosa de todos los edificios públicos, sagrados y profanos de esta muy noble, muy leal, muy heroica e invicta ciudad de Sevilla, y de muchas casas
} 
necesidades, por lo que los patronos encargados de su administración, el prior del Monasterio de la Cartuja y los priores de San Isidoro del Campo y San Jerónimo de Buenavista, denominados por algún autor como el «triunviro monacal», ${ }^{12}$ iniciaron la petición a algunos de los libreros radicados en la ciudad. Gracias a estos encargos se conocen bien su participación dentro del circuito hospitalario sevillano, aunque no se puede precisar mucho ya.

Unas de las primeras noticias referidas a libros de esta índole, y relativa al citado establecimiento, datan de una visita realizada entre los días 9 y 10 de septiembre de 1541, en la que se tomó cuentas al administrador y mayordomo Pedro Hernández, clérigo, anotándose de manera puntual libros destinados al servicio litúrgico, que estaban depositados en la iglesia y la sacristía:

Yten, un misal de papel de letra de molde enquadernado. Yten, un libro baptisterio de papel de letra de molde para administrar los sacramentos... un libro officerio... de papel puntado, en que ay çiertos officios, enquadernado. Iten, cinco quinternos de letanía y cantoría de letra de mano en pergamino, en que está todo el officio de la Dominica in albis con bísperas primeras, enquadernado en tablas sin cuero. ${ }^{13}$

Este es uno de los pocos inventarios en los que se citan libros para el servicio del altar, por lo que se hace imprescindible la consulta de los libros de gasto para obtener algunos datos sobre la compra de esta tipología libraria; así, otra de las primeras noticias datan de 1596, año en el que consta la adquisición de un libro de canto llano «de las fiestas de esta casa, que tiene cuarenta ojas de pergamino» y que costó 110 reales de vellón, encuadernándose después por 30 reales y 8 maravedís. ${ }^{14}$ Parece que este libro estuvo en uso hasta septiembre de 1619 cuando se adquirió uno nuevo al librero Simón Rodríguez: «libro de canto de todas las fiestas, que tiene obligación esta cassa de dezir y cantar en cada vn año» por 530 reales, encuadernado en cuero de venado y guarnecido de metal, con las hojas de pergamino, como indica la correspondiente partida de ese año. ${ }^{15}$

En 1721 los oficiales del hospital sevillano renovaron parte de los libros que servían para el uso de las misas, sobre todo el que se empleaba para el coro de la iglesia. Gracias a la existencia de esta data se conoce que la participación de los religiosos de los monasterios vinculados al hospital tuvo que ser más estrecha de lo que pudiera pensarse en un principio; así, además de que ejercían el patronazgo sobre el establecimiento y que, de forma ocasional,

particulares, con todo lo que les sirve de adorno artístico, antigüedades, inscripciones y curiosidades que contienen. Sevilla, José Hidalgo y Compañía, 1844, p. 251.

12 Chueca, Los hospitales de Sevilla, p. 97.

13 ADPSE. Hospital de las Cinco Llagas, Sec. Fundación y gobierno, leg. 1, doc. 6, s.f.

14 ADPSE. Hospital de las Cinco Llagas, Sec. Contabilidad, leg. 111, s.f.

15 ADPSE. Hospital de las Cinco Llagas, Sec. Contabilidad, leg. 114, f. 66v.

Titivillus, ISSN 2387-0915, ISSN-e 2603-9966, 2 (2016), pp. 157-178 
algunos de sus monjes fueron comisionados para realizar las cuentas y participar en otras materias relativas al gobierno y a la administración, la pericia de algunos de ellos en la puesta por escrito de libros y en su iluminación significó que el triunvirato monacal encargara algunas de estas obras a los monjes de sus cenobios. No en vano, consta que en ese año se abonaron 181 reales y medio a fray José de Arizaga, del Monasterio de San Isidoro del Campo, por dieciocho hojas escritas en pergamino con «punto y yluminadas, añadidas al libro grande del coro», recayendo en el mismo la puesta por escrito en pergamino y la decoración de otros dos libros en cuarto para la iglesia, cobrando por este concepto 6.171 reales. Las hojas escritas en 1721 se añadieron al cantoral existente, ya que en ese mismo año consta una partida que indica el descargo de 109 reales a un librero "por enquadernar vn libro grande de coro y pergamino para 18 ojas que se le añadieron». En esta misma data se hizo constar que los otros dos libros escritos por el jerónimo eran uno del oficio de difuntos y el otro de oraciones «que se dicen el día de la junta». ${ }^{16}$

Naturalmente, muchos de los libros destinados a las celebraciones litúrgicas fueron corregidos y enmendados, añadiéndoseles las novedades del Ritual Romano, introducidas por el Concilio de Trento. Por lo general, los misales, que encargaron los ministros del Hospital de las Cinco Llagas, estaban impresos, porque la universalidad del rito católico facilitaba que las iglesias y los sacerdotes pudiesen adquirir libros en este formato. No sucedía lo mismo con aquellos libros que contenían oraciones particulares, que se habían introducido en el establecimiento, como resultado de las prácticas que se hacían en memoria de los difuntos o festividades propias del centro, como tampoco podían ser impresos aquellos libros, como el de oraciones que se decían durante la celebración de las juntas de gobierno, ya que éstos respondían a unas características inherentes a las prácticas devotas que los patronos fueron introduciendo con el paso de los años. Por este motivo, la información que se refiere a los misales suele ser más escueta en los libros contables; de esta manera, hay datos que permiten corroborar la compra de un misal el 29 de marzo de 1609, «ynpreso en Madrid en este año», que costó 58 reales; ${ }^{17}$ otros dos de «Plantino», que se pagaron a Antonio de Toro en 1622 por 12 ducados; ${ }^{18}$ o el libro de rezo para la sacristía, que se encargó el 4 de enero de 1695

16 ADPSE. Hospital de las Cinco Llagas, Sec. Contabilidad, leg. 129, f. 100 y 102.

17 ADPSE. Hospital de las Cinco Llagas, Sec. Contabilidad, leg. 112, f. 66v. Pudiera tratarse del Ceremonial de la missa: en el qual se ponen todas las rubricas generales, y algunas particulares del misal romano, que diuulgo Pio V y mandó reconocer Clemente VIII... recopilado por Fray Iuan de Alcocer de la Orden de San Francisco... En Madrid, en la Imprenta Real (Por Iuan Flamenco), a costa de Pedro Lisao..., 1609.

18 ADPSE. Hospital de las Cinco Llagas, Sec. Contabilidad, leg. 114, f. 50. Del Missale romanum: ex decreto Sacrosancti Concilii Tridentini restitutum, Pii V. Pont. Max. iussu editum: additis aliquot ss. officiis ex praecepto, impreso en Amberes en la oficina de Cristóbal Plantino entre 1572 y 1587.

Titivillus, ISSN 2387-0915, ISSN-e 2603-9966, 2 (2016), pp. 157-178 
al librero Pedro de Santiago. ${ }^{19}$ Con todo, las novedades que se fueron añadiendo al ceremonial eclesiástico católico posibilitaron que se comprasen cuadernillos sueltos, ya impresos o, incluso, escritos a mano, que, generalmente, eran encuadernados en otros misales más antiguos con el fin de adecuarlos. Así, el 16 de diciembre de 1689 se dieron a Francisco José de Pedrosa 8 reales por «aderezar un misal de la iglesia»; 20 el 6 de diciembre de 1699 se sacaron de las arcas 36 reales para pagar al librero Juan José Gómez por «enquadernar de nuebo con tablillas y vadana y manecilla un missal de la yglesia y echarle canon ${ }^{21}$ nuebo y añadirle un quaderno de missas nueuas»;22 asimismo, entre el 31 de octubre y el 11 de noviembre de 1717, se dieron al oficial de librero Manuel de Navas 165 reales por el «aliño, enquadernación y añadir cánones, comunes y santos nuebos a quatro misales de la sacristía de este hospital». ${ }^{23}$

Uno de los libros más interesantes, desde el punto de vista de su confección material, es el llamado Libro de oraciones del Hospital de San Lázaro, que bien pudiera considerarse un obituario. Este ejemplar, del que se conoce su existencia gracias al exhaustivo inventario existente, ${ }^{24}$ ha pasado totalmente desapercibido para la historiografía, desconociéndose, hasta el momento, su cronología, debiéndose situarse a mediados del siglo XVI. El libro debe de ser englobado dentro de la tipología libraria de la que se está tratando, esto es, libros para un uso litúrgico.

Como se ha apuntado, la Casa de San Lázaro hundía sus raíces en la Edad Media, pudiéndose considerar como el decano de los establecimientos sevillanos. De fundación real, el hospital permaneció bajo dicha jurisdicción hasta el siglo XIX, momento en el que muchos de los establecimientos de caridad pasaron a depender del Estado. Desde su creación y organización, los reyes lo privilegiaron y lo dotaron ampliamente para el sostenimiento de la pía institución en la que se recogieron a los malatos del Arzobispado de Sevilla y Obispado de Cádiz. Las primeras constituciones de las que se tienen constan-cia datan del 15 de diciembre de 1393, en el reinado de Enrique III, y sirvieron como modelo a las de otros establecimientos de similares características que se fundaron en el Nuevo Mundo. 25

19 ADPSE. Hospital de las Cinco Llagas, Sec. Contabilidad, leg. 125, f. 91.

20 ADPSE. Hospital de las Cinco Llagas, Sec. Contabilidad, leg. 124, f. 94v.

${ }^{21}$ Parte de la misa, que empieza con el Te igitur y acaba con el Paternoster.

22 ADPSE. Hospital de las Cinco Llagas, Sec. Contabilidad, leg. 126, f. 432.

23 ADPSE. Hospital de las Cinco Llagas, Sec. Contabilidad, leg. 128, f. 81v.

${ }^{24}$ Carmen BARRiga Guillen [et al.], Hospitales y centros benéficos sevillanos. Inventarios de sus fondos, Sevilla, Diputación Provincial de Sevilla, 1997, p. 213.

${ }^{25} \mathrm{M}^{\mathrm{a}}$ del Carmen Borrego PlÁ, «El Hospital de San Lázaro de Sevilla y su proyección indiana» en Bibiano TORRES RAMíreZ (coord.), La influencia andaluza en los núcleos urbanos 
El texto constitucional contiene algunas pautas organizativas en las que se daban instrucciones concretas para que la vida del enfermo quedase totalmente organizada. De esta forma, las razones justificativas por las que existiría un libro de estas características se encuentran ya en estas constituciones; así, por razón del patronazgo regio, Enrique III habría incluido una serie de normas por las que los leprosos debían de elevar oraciones por los soberanos de Castilla. En concreto, tanto el título XXXVIII como el XXXIX se especificó la obligatoriedad de que un capellán dijese diariamente una misa «por las ánimas de los reyes... que fizieron e dotaron la dicha casa». Además, en compañía del mayoral, nombre con el que se conocía al administrador del hospital y que actuaba como alter ego del soberano, los malatos debían acudir a la iglesia del establecimiento para realizar una serie de oraciones por la salud e intención, tanto de los reyes como de todos los benefactores que había dejado algún patrimonio a la institución, existiendo penas económicas a aquellos que incumplieran este mandato constitucional:

Otrosí, mando e ordeno que por quanto sienpre fue de buen vso e de buena costunbre en la dicha casa de fazer oraçión por las ánimas de los reyes mis progenitores, donde yo vengo, que fizieron e dotaron la dicha casa e la preuillejaron e dieron grandes franquesas e libertades e aças, propios e rentas para sostenimiento de los dichos enfermos, e por la mi vida e salud e por todos los bienfechores della, así biuos como finados, en el portal... de la dicha capilla de Sennor Sant Lázaro, mando que, de aquí adelante, que después que fuere tannida la canpana mayor, según que sienpre fue acostunbrado, quel dicho mayoral, que agora es o será de aquí adelante, con todos los enfermos e enfermas de la dicha casa que estén presentes en la dicha oraçión con sus cuentas en sus manos resando sus Pater Nostres (sic), con la mejor deuoçión que pudieren por las ánimas de los dichos reyes, como dicho es, e por la mi vida e salud e por todos los bienfechores de la dicha casa e enfermos della. E otrosí, que luego, acabante la dicha oración, que sean todos temidos de entrar en la dicha capilla a oyr la Salue Regina... ${ }^{26}$

Sin duda, el libro representa uno de los mejores ejemplos del patrimonio bibliográfico que en la actualidad atesora la Diputación Provincial de Sevilla. De uso exclusivo para las oraciones diarias que los malatos brindaban por sus benefactores y patronos, todo apunta a que solo existió un ejemplar que era utilizado indistintamente por el clérigo o mayoral como responsable, ya que su uso se extendió en el tiempo, percibiéndose continuas anotaciones y ampliaciones del texto a medida que había nuevos donantes y patrocinadores.

El libro se realizó después del reinado de los Reyes Católicos, momento en el que se produjo una importante coyuntura interna en la institución. Una crisis de gobierno en la que fue necesaria la intervención real con la subsi-

americanos, Huelva, Universidad de Santa María de la Rábida, 1987, pp. 164, 175, 177-179 y 181-196.

${ }^{26}$ ADPSE. Pergaminos, 228, f. 12.

Titivillus, ISSN 2387-0915, ISSN-e 2603-9966, 2 (2016), pp. 157-178 
guiente reforma constitucional. ${ }^{27}$ De este modo, en las páginas introductorias del libro se recoge la memoria de los privilegios y el motivo del nacimiento del mismo, aludiéndose a la confirmación hecha por los Reyes Católicos:

En el nombre de Dios, Padre e Fijo e Spíritu Sancto, Tres Personas e Un Solo Dios Verdadero, que biue e reyna para siempre sin fín, e de la Bienauenturada Virgen Gloriosa, Nuestra Sennora Sancta María, Su Bendita Madre, a la qual nosotros tenemos por Sennora e por Abogada en todos nuestros fechos, e a honrra y seruicio del Bienauenturado Mártyr Sennor San Lázaro, e de todos los sanctos e sanctas de la corte celestial. Aquí comiença el libro de la oración, que el mayoral e enfermos de la Casa de Sennor Sant Lázaro, que es cerca de los muros de la muy noble e muy leal cibdad de Seuilla, hazen de cada vn día por las ánimas de los reyes de Castilla e de León, de gloriosa memoria, cuyas ánimas Dios aya, que hizieron e doctaron la dicha casa e la apropiaron e preuilejaron e dieron munchas franquezas e exempciones e libertades, que la dicha casa oy día tienen, los quales confirmaron e mandaron guardar el rey don Fernando e la reyna donna Ysauel, nuestro señores que Dios aya, e por lo bienfechores della, ansí biuos e finados, e enmienda e satisfación de todos los bienes a la dicha casa e a ellos fechos. ${ }^{28}$

El libro de oraciones del Hospital de San Lázaro de Sevilla destaca por el virtuosismo de su factura y por sus características intrínsecas: hojas de pergamino y encuadernación de cuero marrón con filete dorado y manecillas metálicas, tamaño en cuarto, ya que se debía ser diariamente sostenido por quien dirigía la oración. Alterna la tinta roja para las rúbricas con el encabezamiento de cada oración, y la negra para el texto, empleándose una correcta littera textualis en su variedad rotunda, o lo que es lo mismo, aquella escritura en la que se evidencian las características conceptuales de la gótica, como las distinguió Gerard Isaac Lieftinck en 1953, cuando se celebró en París el I Coloquio Internacional de Paleografía Latina. ${ }^{29}$ En este sentido, sus características

${ }^{27}$ La crisis de gobierno estuvo motivada al designar los Reyes Católicos, el 7 de enero 1476, como mayoral del lazareto al comendador Rodrigo de Maldonado por fallecimiento del que lo había sido anteriormente, Alfonso de Carrión (ARChivo General DE SimanCAS (AGS), Sec. Registro General del Sello, leg. 147.601, 24). Como quiera que, aunque el mayoral era de designación regia, los enfermos debían confirmar el nombramiento, éstos se opusieron, acogiéndose a una real facultad dada en 1456 por Enrique IV, y nombrando a Juan de Sosa. Por este motivo se produjo un desgobierno en el establecimiento, al que le siguió un litigio entre ambos mayorales que se alargó en el tiempo (AGS. Sec. Registro General del Sello, leg. 147.705, 203). Habría que esperar a 1491 para que la autoridad real se restableciera en la institución piadosa, nombrando en sustitución de los anteriores a un tal Pedro de Frías (AGS. Sec. Registro General del Sello, leg. 149.103, 116).

28 ADPSE. Hospital de San Lázaro, Sec. Varios, lib. 52, pp. 1-2.

${ }^{29}$ Gerard Isaac LIEFTINCK, «Pour une nomenclature de l'escriture livresque de la période dite gothique», Nomenclature des écritures livresques du IXe au XVI siècle. I Colloque International de Paléographie Latine, Paris, 28-30 avril, 1953, pp. 15-34.

Titivillus, ISSN 2387-0915, ISSN-e 2603-9966, 2 (2016), pp. 157-178 
paleográficas concuerdan con las finalidades del libro, como sostiene $\mathrm{M}^{\mathrm{a}}$ del Carmen Álvarez Márquez, quien mantiene que esta escritura solía ser empleada para la confección de misales o libros ordinarios de buena factura, como es el caso (Fig. 1). ${ }^{30}$ Conjuga, magistralmente, una armoniosa alternancia de iniciales puzles rellenas de azul y rojo sobre recuadros afiligrana-dos en rojo y azul con otras secundarias rellenas de azul afiligranadas en rojo o rellenas de rojo afiligranadas en azul. Puntualmente, el manuscrito se iluminó con los blasones y armas heráldicas del asistente de Sevilla entre 1558 y 1565, Francisco Chacón y su esposa, señores de Casarrubios y Arroyomolinos, uno de los matrimonios benefactores del centro más importantes (Fig. 2). ${ }^{31}$

Una de las particularidades de este libro es que estuvo en uso hasta bien entrado el siglo XVIII, por lo que es fácil distinguir las diferentes manos y momentos en los que se escribió. En este sentido, los continuos añadidos que se le hicieron, aunque no desvirtuaron su sentido primigenio, sí cambió el estilo con el que había nacido, observándose en fechas más modernas escrituras humanísticas y usuales, empleándose una composición menos cuidada. Gracias a algunas anotaciones, se puede afirmar que el libro estuvo utilizándose hasta 1775, año en el que se registró una del cura y capellán Bartolomé Rengel. Aunque el manuscrito ha llegado en buen estado hasta la actualidad, existen algunos folios con pérdidas de tinta que dificultan su lectura, así como páginas que fueron extirpadas, perdiéndose toda memoria de algunos de los patrocinadores del establecimiento. Por este motivo, uno de los capellanes llegó a escribir «aquí faltan dos fojas, roguemos por los bienhechores que en ellas se contenían». ${ }^{32}$

Como hospital privilegiado por los reyes, muchos personajes de la alta nobleza y del patriciado urbano, siguiendo el ejemplo de los monarcas, déjàron parte de su patrimonio para el sostenimiento de los malatos andaluces, inscribiéndose en las hojas del manuscrito sus nombres. Entre ellos hay que mencionar al adelantado Diego Enríquez de Ribera, Alvar Pérez de Guzmán o Per Afán de Ribera y Pedro de Estúñiga.

Sin duda, debió de existir alguna normativa regia para la inscripción de benefactores en el libro, ya que un texto alude a que para ello la donación debía superar los 2.000 maravedís en bienes muebles o raíces. Con todo, no parece que esta circunstancia se llegase a observar en todo momento, puesto que existen oraciones en las que, además de consignarse el nombre del do-

\footnotetext{
$30 \mathrm{M}^{\mathrm{a}}$ del Carmen Álvarez MÁRQUEZ, «Escritura latina en la Plena y Baja Edad Media. La llamada "Gótica Libraria" en España», Historia. Instituciones. Documentos, 12 (1985), pp. 377 410 y «El libro en la Baja Edad Media. Su caligrafía» en $M^{a}$ Encarnación MARTíN LÓPEZ, Vicente GARCÍA LOBO (coords.), Las inscripciones góticas. II Coloquio Internacional de Epigrafía Medieval, León del 11 al 15 de septiembre de 2006, León, Corpus Inscriptionum Hispaniae Mediaevalium, 2010, pp. 263-332.

31 ADPSE. Hospital de San Lázaro, Sec. Varios, lib. 52, pp. 12-13

32 Ibidem, p. 72.
} 
nante, se registró su dádiva, que, ocasionalmente, no superaba dicha cantidad, como fue el caso del escritor de libros Luis Puertocarrero, en cuyo testamento destinó la cantidad de 7 maravedís. ${ }^{33}$

\section{Libros para la administración de enfermos}

Junto a los libros destinados al servicio litúrgico, los hospitales españoles, y, por ende, los sevillanos, debían de tener otra tipología libraria para la atencón de los enfermos. Dentro de esta categoría hay que distinguir aquellos libros confeccionados para la administración de los enfermos, que estaban, por lo general, en manos de los oficiales del establecimiento, así como del personal sanitario (físicos, boticarios, enfermeros, matronas, etc.). Las diferen-tes constituciones establecían a la perfección los que debían existir, como libros registros de enfermos, en los que se escribía el nombre, así como su estado, dolencia y otras noticias de importancia. Los registros de enfermos constituyen uno de los vestigios documentales y librarios más antiguos; así, en la Antigüedad Clásica, ya se tendía a realizar estos tipos de registros, existiendo evidencias arqueológicas por las que en el célebre templo de Epidauro, en el que se vene-

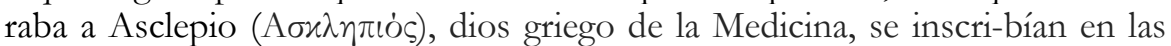
bases de sus columnas el nombre de algunos enfermos, sus dolen-cias, el tratamiento, apuntándose si éstos habían sanado o no. ${ }^{34}$

Además de los libros administrativos destinados a la oficialía hospitalaria, cuya naturaleza se obvia en este artículo, hay que tener presente que los establecimientos sanitarios debieron de poseer algunos libros medicinales para el servicio del personal responsable. Desde esta perspectiva, sorprende que en la hospitalidad sevillana no abunde información sobre este particular, más allá de aquellos libros ubicados en la botica y que servían para la composición de fármacos, ungüentos y drogas. Ya, las constituciones de 1591 del Hospital del Espíritu Santo, escritas por una comisión de médicos, cirujanos, mayordomos y administradores de los establecimientos más impor-tantes de la ciudad por orden del cardenal Rodrigo de Castro, dedicó todo un apartado al gobierno de la botica, así como a los libros que debían de existir para anotar sustancias que servían para componer los preparados médicos. ${ }^{35}$ Lo mismo pueden decirse de otras ordenanzas, como las de 1603 del Hospital de las Cinco Llagas, que ordenaban que se comprasen «todos los libros que fueren neçesarios a la

\footnotetext{
${ }^{33}$ En su testamento, otorgado el 6 de enero de 1579 ante el escribano público de Sevilla Diego Gabriel, se encuentran sus mandas, destinándose la citada cantidad para el lazareto sevillano ( $\mathrm{M}^{\mathrm{a}}$ del Carmen ÁLvarez MÁRQUeZ, El libro manuscrito en Sevilla (siglo XVI), Sevilla, Diputación Provincial de Sevilla, 2000, p. 194).

34 Miguel De la Plata y Marcos, Estudios biográficos-bibliográficos de la Medicina Militar Española, Madrid, Imprenta médica de Manuel Álvarez, 1864, p. 228.

${ }^{35}$ ADPSE. Hospital del Espíritu Santo, Sec. Fundación y gobierno, leg. 2 C, ff. 11v-12.
}

Titivillus, ISSN 2387-0915, ISSN-e 2603-9966, 2 (2016), pp. 157-178 
botica para la conpusiçión de las medeçinas, porque por falta dellos no se yerren».36

Al margen de estos libros y otros de análoga funcionalidad, pocas son las noticias sobre la existencia de bibliotecas especializadas en temas medicinales. Es posible que, ya que el personal sanitario no estaba obligado a residir en el establecimiento, caso de los administradores y mayordomos, éstos se llevasen el material desde sus centros de trabajo, pudiendo consultar los libros de su oficio en sus respectivas residencias. Recientes trabajos han estudiado las bibliotecas personales y especializadas que algunos de estos médicos y cirujanos tenían ya en esta época. ${ }^{37}$

Sin embargo, no parece razonable pensar que los hospitales estuvie-sen desabastecidos de material bibliográfico sobre particularidades médicas; así, una de las pocas referencias documentales a este respecto procede del Hospital de las Cinco Llagas, existiendo una partida económica dedicada a la adquisición, en 1596, del «Método de Luis de Oviedo» por 612 reales. ${ }^{38}$ Empero, las fuentes documentales que se han conservado permiten sostener que lo habitual fue la adquisición de libros en blanco que eran escritos por el propio personal sanitario, no abundando tratados o trabajos médicos que sirvieran como material de apoyo. Uno de los ejemplos que se tienen de la composición de obras de particular interés para la elaboración de medicamentos por parte de los boticarios, procede del Hospital de San Hermenegildo, existiendo a tal efecto un formulario impreso, hecho en 1763.39

Aunque la producción libraria de temática sanitaria adquirió un considerable auge durante la Edad Moderna en España, viviendo su máximo esplendor durante el Siglo de Oro, algunos autores han puesto de relieve este hecho, afirmando que el 32,87\% de los libros dedicados a ciencias fueron escritos por médicos y cirujanos, contabilizándose en ese período un total de cuatrocientos noventa autores. ${ }^{40}$ Sin embargo, la paulatina importancia de la

36 ADPSE. Hospital de las Cinco Llagas, Sec. Fundación y gobierno, leg. 1 A, doc. 3, s.f.

37 Mercedes FernándeZ-CARrión, José Luis VAlVERdE. Farmacia y sociedad en el siglo XVI, Sevilla, Ayuntamiento de Sevilla, 1985, p. 31. Recientemente, la profesora $\mathrm{M}^{\mathrm{a}} \mathrm{del}$ Carmen Álvarez Márquez, ha logrado documentar algunas de las bibliotecas más interesantes de la Sevilla de estos años ( $\mathrm{M}^{\mathrm{a}}$ del Carmen Álvarez MÁrquEZ, Bibliotecas privadas de Sevilla en los inicios de la Edad Moderna, Zaragoza, Pórtico, 2014, pp. 366-452).

38 ADPSE. Hospital de las Cinco Llagas, Sec. Contabilidad, leg. 111, s.f. Se refería a célebre obra de Luis de Oviedo, Methodo de la collection y reposicion de las medicinas simples, y de su correction y preparación..., impreso en Madrid en 1581 por Alonso Gómez y en 1595 por Luis Sánchez.

39 Joaquín Herrera DÁvila, El Hospital del Cardenal de Sevilla y el doctor Hidalgo de Agüero: visión histórico-sanitaria del Hospital de San Hermenegildo (1455-1837), Sevilla, Fundación Cultura Andaluza, 2010, pp. 318 y ss.

40 Una de las fuentes más utilizadas para pulsar el estado bibliográfico español en esta etapa ha sido la Biblioteca Hispana Nova de Nicolás Antonio, que abarca toda la producción 
temática, unida al espíritu humanista y científico, no hizo más que potenciar obras de esta índole.

Un caso particular es el estudiado por Antonio Claret García Martínez, quien, en un artículo publicado en 2004, menciona una obra publicada, en Madrid el año 1625, por el enfermero Andrés Martínez, bajo el título Instrucción de Enfermeros, localizada en la Biblioteca Universitaria de Sevilla. En ella, se trata de la puesta por escrito de procedimientos de actuación para el tratamiento de enfermos por parte de los enfermeros pertenecientes a la Mínima Congregación de los Hermanos de los Pobres, conocida popular-mente como los «obregones». Habría que pensar que la obra estuvo en el hospital que la comunidad regentó en Sevilla, llamado el Hospital de Convalecientes de Nuestra Señora del Buen Suceso, en la collación de Santa Catalina. Este ejemplo constituye un caso aislado, que muestra la especialización y dedicación de una comunidad religiosa al servicio de los pobres enfermos, a semejanza de la Congregación de San Juan de Dios, también representada en Sevilla por el Hospital de Nuestra Señora de la Paz. Este tratado, y otros impresos en estos años por los «obregones», dan testimonio del ascenso de los enfermeros y de la «necesidad de una formación» por parte de éstos. ${ }^{41}$

En la hospitalidad hispalense, más allá de los libros que los oficiales y personal sanitario elaboraban para la asistencia a los enfermos, no parece que hubiese bibliotecas destinadas a la consulta de los profesionales fuera aparte de algún que otro tratado en particular. Una excepción la constituye el Real Hospital de Santiago de Compostela, cuyas constituciones de 1524 ya preveían la organización de una biblioteca de temática variada, compuesta por libros de Teología, Artes, Derecho, Medicina «y otros libros de romance de buenas doctrinas».42

En Sevilla, tampoco hay evidencias de la existencia de bibliotecas para el uso y entretenimiento de los pacientes, característica que sí se dieron en algunos hospicios castellanos, como el de Veracruz de Medina de Pomar

hispano-lusa entre 1500-1684. Ricardo García Cárcel, tomando las tesis de algunos historiadores como José María López Piñero o Julio Caro Baroja, ha puesto de relieve la importancia que adquirió la temática sanitaria en la producción libraria, aunque muy por delante de la impresión de estos tratados siguieron estando las obras de carácter sacro y otras del gusto del momento (Ricardo GarCía CÁrCEL, Las culturas del Siglo de Oro, Madrid, Historia 16, 1999, pp. 119-122).

41 Antonio Claret García MartíneZ, Presentación y análisis de la obra "Instrucción de enfermeros" de Andrés Fernánder, 1625. Aproximación a la Enfermería Española de los siglos XVI-XVIII, Madrid, Consejo General de Diplomados de Enfermería, 1992, pp. 251 y 257-258.

42 Constituciones del Gran Hospital Real de Galicia, hechas por el señor emperador Carlos Quinto, de gloriosa memoria, Santiago de Compostela, Imprenta de Sebastián Montero y Frayz, 1775, p. 78.

Titivillus, ISSN 2387-0915, ISSN-e 2603-9966, 2 (2016), pp. 157-178 
(Burgos), donde existió una que se organizó, a fines del siglo XVI, gracias a la donación que hizo el I Conde de Haro.43

Un caso aislado lo constituye el Hospital del Pozo Santo, un establecimiento que se fundó en Sevilla en la segunda mitad del siglo XVII y que estuvo destinado a mujeres impedidas. El centro estaba atendido por una comunidad de religiosas y, quizás, por esta razón tuvo una biblioteca de la que se ha conservado un inventario, elaborado en 1701, que incorporamos en el apéndice documental, y constituido, en su mayoría obras de piedad y hagiográficas, conforme a las necesidades que las religiosas requerían para su vida de recogimiento. De esta forma, se aprecia que en su mayoría los volúmenes que aparecen recogidos guardan como común denominador dicha temática, destacando la presencia de las obras de la madre Ágreda, San Francisco de Paula o Santa Gertrudis, además de tres de Juan de Palafox y Mendoza, dos tomos de la primera parte del Flor Sanctorum de Alonso de Villegas y otro par de dos trabajos diferentes de Juan Eusebio Nieremberg. Junto a ellos, hay que destacar la Breve relación de la muerte, vida y virtudes del venerable caballero D. Miguel de Mañara y Vicentelo de Leca, compuesto por el jesuita Juan de Cárdenas, autor que recogió la vida de este venerable sevillano que gobernó y reformó el importante Hospital de la Caridad. Hay que deducir, que la biblioteca se componía exclusivamente de libros impresos, no existiendo alusión alguna a que se tratasen de manuscritos (Apéndice I).

Libros para el gobierno hospitalario: los protocolos de bienes

Los hospitales no sólo fueron consumidores y creadores de libros religiosos y sanitarios. Es obvio que, como toda corporación o institución, precisaron de un instrumental librario y documental, puesto al servicio del gobierno y la administración. Se obvia el estudio de libros comunes a otras instituciones, como libros de regla, libros de acuerdo o económicos, porque sus características no presentan ni un formato ni un estilo novedoso. No puede decirse lo mismo de una tipología de códice, cuyo uso se extendió entre la hospitalidad hispalense y que se denominó genéricamente como libro protocolo de bienes. En ellos, se registró, de forma sustanciada, las diferentes propiedades, rentas y privilegios que permitían el funcionamiento de los distintos establecimientos, llegándose a redactar las primeras historias y crónicas fundacionales de cada uno de ellos. ${ }^{44}$

43 Diego Arsuaga Laborde, «Los libros donados por el primer Conde de Haro al Hospital de la Vera Cruz de Medina de Pomar. Un testimonio de la bibliofilia de un magnate en la Castilla de mediados del siglo XV», Espacio, tiempo y forma. Serie III. Historia Medieval, 25 (2012), pp. 85-118.

${ }^{44}$ Pablo Alberto Mestre Navas, «Los protocolos de bienes del Archivo de la Diputación de Sevilla: memoria corporativa e instrumentos de gobierno y gestión», Actas X Jornadas de 
No interesa aquí señalar su importante uso desde el punto de vista de la gestión económica y del gobierno, tampoco esbozar un estudio de carácter diplomático de los mismos, sino la increíble importancia que tuvieron, llegandose a transformar en el libro principal de cada una de las instituciones, prestándose especial atención a su decoración y escritura, sobre todo durante los siglos XVII y XVIII. Para ello, los oficiales encargaban a calígrafos, iluminadores y libreros su cuidada confección. El excesivo exorno que los códices adoptaron por aquel tiempo puede deberse a dos razones principales: en primer lugar, los libros eran objeto de pesquisa por los visitadores eclesiásticos y reales, razón por la que los hospitales se afanaban en exornarlos primorosamente, y, en segundo lugar, los protocolos de bienes fueron un instrumento demostrativo del poder de cada uno de esos establecimientos, causa que les llevó a confeccionar libros que compitieran con los de otros hospitales. 45

Se han conservado innumerables códices de este tipo, aunque quizás dos testimonien algunas de las características extrínsecas que se están apuntando: el del Hospital de la Caridad, en cuya portada algunos expertos han apuntado a una más que posible autoría del genial artista barroco Juan Valdés Leal (Fig. 3), ${ }^{46}$ y el de la Casa Cuna, obra pía destinada a la crianza de los niños expósitos. En ambos casos, se evidencia la participación de libreros y calígrafos, que dotaron a los volúmenes de un rico muestrario de iniciales, ilustraciones y grafías de distintos tipos.

El protocolo de bienes de la Casa Cuna es uno de los mejor documentados, datándose en 1695 las primeras noticias sobre su composición, quedando encargado de ello José Ponce, quien no parece que lo concluyera, ya que se le apremió en distintas ocasiones, determinándose que fuese José de la Torre, ${ }^{47} \mathrm{a}$ quien se le abonaron 3.300 reales por su confección, concluyéndose sus trabajos en 1699.

La ilustración principal muestra el emblema corporativo, con una gran cuna en la que reposan varios párvulos expósitos (Fig. 4). Los protocolos de bienes son uno de los ejemplos con los que los hospitales sevillanos se presentan como productores de libros manuscritos durante la Edad Moderna, con singularidades propias y características identificativas evidentes.

bistoria sobre la provincia de Sevilla. Pasado y presente de la Diputación de Sevilla. Su proyección en los pueblos de la provincia, Sevilla, ASCIL, 2013, p. 107.

45 Pablo Alberto Mestre NAvas, «Decoración, ilustración e iluminación en el patrimonio documental de los hospitales sevillanos: los libros de protocolo de bienes», en María del Amor Rodríguez Miranda (coord.), Nuevas perspectivas sobre el barroco andalur: Arte, tradición, ornato y símbolo, Córdoba, Asociación "Hurtado Izquierdo", pp. 429-440.

${ }^{46}$ Enrique Valdivieso GonzÁlez y Juan Miguel Serrera Contreras, El Hospital de la Caridad de Sevilla, Sevilla, Server Cuesta, 1982, pp. 105-106.

${ }^{47}$ ADPSE. Casa Cuna, Sec. Fundación y gobierno, lib. 1, f. 34.

Titivillus, ISSN 2387-0915, ISSN-e 2603-9966, 2 (2016), pp. 157-178 


\section{Conclusiones}

Durante el Antiguo Régimen, los establecimientos sanitarios estuvieron bajo la órbita de influencia de la Iglesia y de prácticas devotas que veían en el auxilio ajeno la salvación de sus almas. Por este motivo, durante dicho período tanto la Iglesia, como la Corona y algunos particulares se afanaron en fundar, proteger, amparar y patrocinar hospitales. En este sentido, el fenómeno hospitalario no solo se circunscribe a instituciones exclusivamente sanitarias, sino piadosas.

Tales circunstancias condicionaron una producción libraria muy particular; así, junto a libros destinados a la curación de enfermos, en cuya composición participaron de manera activa los médicos y boticarios, hubo otra de carácter religiosa. Dentro de esta realidad habría que señalar libros propios para la administración de sacramentos, como otros orientados a la sanación del alma o preparar a ésta a morir, caso del Ars moriendi. Además, los hospitales sevillanos contaron con ejemplares manuscritos dedicados a la oración en comunidad de los enfermos, destacando el obituario del Hospital de San Lázaro, cuya hechura quedaba recogida en sus constituciones medievales de 1393.

Sin duda, el mantenimiento de la pía institución, así como la de los hospitalizados, dependía, en buena manera, del remanente económico que legados y donaciones proporcionaba. Los hospitales fueron grandes propieta-rios de inmuebles y bienes rústicos que se diseminaban por toda la geografía del antiguo reino de Sevilla y de otras localidades y zonas limítrofes. Para ejercer ese control patrimonial, los oficiales de los establecimientos idearon un libro, que se denominó protocolo de bienes, para controlar sus amplias posesiones. Estos códices diplomáticos, de hermosa factura, adoptaron múltiples funcionalidades desde el punto de vista del gobierno, siendo decorados con trabajadas ilustraciones y caligrafías que representaban el poder de unas instituciones de antigua raigambre.

A pesar de ser lugares dedicados al tratamiento de enfermedades, sorprende la escasez de noticias existentes, para el caso sevillano, de libros medicinales y tratados farmacológicos. Esta razón puede deberse a que los médicos, a diferencia de administradores y sacerdotes, no residían con carácter permanente en el edificio, por lo que no sería extraño que contasen en sus propios domicilios con libros que paliasen esta deficiencia para el desarrollo de su actividad profesional.

Con todo, es obvio que la hospitalidad sevillana disfrutó de libros de botica y otros análogos en los que los responsables anotaban con carácter puntual los recetarios de drogas y ungüentos que debían suministrarse a los pacientes y enfermos, conformando bibliotecas de consulta y acceso restringido.

Por otra parte, el hecho de que algunos hospitales estuviesen bajo la administración de congregaciones religiosas trajo como consecuencia la existencia de bibliotecas, como las Hospital de Pozo Santo, en la que se 
recopilaron obras de carácter religioso, es decir, más para un uso destinado a la comunidad que a los profesionales de la Medicina.

En conclusión, el mundo del libro en los hospitales hispalenses puede circunscribirse a tres funciones básicas, recogidas a lo largo de este artículo: libros para rezar, libros para asistir y libros para administrar y gobernar.

\section{Apéndice I: La biblioteca del Hospital del Pozo Santo (1701)}

- [1-3] «3. Primeramente, las obras de la madre Ágreda en tres tomos de folio [María de Jesús de ÁGREDA, Mystica ciudad de Dios, milagro de su omnipotencia, y abismo de la gracia: historia divina y vida de la Virgen Madre de Dios... manifestada... por la misma Señora à su esclava Sor Maria de Jesus abadesa de el Convento de la Inmaculada Concepción de la villa de Agreda..., de la regular observancia de... S. Francisco... III partes, de la que se hicieron varias ediciones en diferentes lugares, a lo largo del siglo XVII]

- [4] 1.Yten, Vida de la venerable virgen doña María de Escobar, en un libro de folio Probablemente, Francisco DE PERALTA, Panegyrico a las piadosas memorias de la venerable matrona D. Maria de Escobar, Valladolid, Iuan Lasso, 1633].

- [5] 1. Yten, Coronica de la Prouinzia de los Ángeles, en un tomo de a folio [Andrés DE GuAdalupe, Historia de la Santa provincia de los Angeles de la... orden de... San Francisco..., Madrid, Mateo Fernández, 1662].

- [6-7] 2. Yten, dos tomos de a folio de la Vida de Santa Gertrudis [Vida y revelaciones de Santa Gertrudis la Magna monja de la Orden del patriarca San Benito: libro intitulado insinuacion de la Divina Piedad y embaxada de la Divina misericordia: con la quarta y quinta parte en que se contiene la vida y virtudes de la misma santa traducido de latin en romance por el Rmo. P.M. Fe Leandro de Granada y Mendoza..., Madrid, Melchor Álvarez, 1689].

- [8] 1. Yten, Corónica (sic) de San Francisco de Paula, en un tomo de a folio Pedro DE MENA, Chronica del nacimiento, vida y milagros y canonizacion del beatissimo Patriarca San Francisco de Paula, fundador de la Sagrada Orden de los Minimos..., Madrid, Licenciado Castro, 1596].

- [9] 1. Yten, un libro de a folio intitulado Prado espiritual [Juan Basilio SANTORO, Prado espiritual: los tres primeros libros del Prado espiritual: recopilados de antiguos y clarissimos y santos doctores por el doctor..., imposible precisar la edición] - [10] 1. Yten, un libro de a folio de las Obras de Ludovico Brosio [Ludovico BLOIS, Las obras de Ludovico Blosio, abad de S. Benito traduzidas por fray Gregorio de Alfaro... de la misma Orden, imposible precisar edición].

- [11] 1. Yten, otro libro de a folio de la Vida de la venerable virgen doña María de Escobar [Probablemente, Francisco DE PERALTA, Panegyrico a las piadosas memorias de la venerable matrona D. Maria de Escobar, Valladolid, Iuan Lasso, 1633].

Titivillus, ISSN 2387-0915, ISSN-e 2603-9966, 2 (2016), pp. 157-178 
- [12] 121. Yten, Coronica de la Prouinzia de los Ángeles, en un tomo de a folio [Andrés DE GuADAlupe, Historia de la Santa pronincia de los Angeles de la... orden de... San Francisco..., Madrid, Mateo Fernández, 1662].

- [13] 1. Yten, un libro de a folio de Varones ilustres de la Compañía de Iesús, tomo $2^{\circ}$ Juan Eusebio Nieremberg, V arones ilustres de la Compañia de Jesús. 2 Misiones de de la China, Goa, Etiopía, Malabar, imposible precisar edición].

- [14] 1. Yten, un libro de a folio de las obras del padre Alonso Rodríguez [Posiblemente, Alonso RODRígueZ, Exercicio de perfeccion y virtudes christianas..., imposible precisar edición].

- [15] 1. Yten, un libro de a folio de la Vida de la madre María de la Antigua [Andrés DE SAN AgUSTÍN, Vida exemplar, admirables virtudes y muerte prodigiosa de la V. Madre... Soror Maria de la Antigua, donada... de el Convento de Santa Clara del Orden de San Francisco en ... Marchena, y ... monja en el de la Mercenarias Descalças de la Villa de Lora...; con los Romances y versos que ... compuso ... dicha V. Madre ..., 1675].

- [17] 2. Yten, dos Flor Sanctorum, ambos libros de la primera parte [Posiblemente, de Alonso DE VILLEGAS].

- [18] 1. Yten, un libro de a folio de la Vida de la madre (en blanco).

- [19] 1. Yten, un libro de a quartilla Espejo místico [Pudiera ser Bernardo DE SANTA MARÍA, Espejo regular, moral, y mistico, en el que se descubren las muchas imperfecciones, y feas alegaciones del Manifiesto legal instrumental del Padre Fray Joseph Torrubia...: manifiesto juridico, canonico historial, que residencia las invenciones del Examen canonico legal de dicho Padre Torrubia, y Fray Bernardo de la Trinidad...: recopilacion de las cartas, y papeles, que se han divulgado en contra de la verdad que se defiende...: y defensa de las bulas de esta provincia y de los privilegios, y bien estàr de la Descalcèr Franciscana...7.

- [20] 1. Yten, otro de a quartilla de la Vida del venerable padre Juan Dáuila [Vida y obras del Venerable Maestro Juan de Avila ..., nuevamente añadido y enmendado por Martín Ruiz de Mesa].

- [21] 1. Yten, otro libro de a quartilla de la Vida de Christo, Nuestro Señor [de Cristóbal DE FONSECA].

- [22] 1. Yten, otro libro de a quartilla intitulado Varón de deseos Juan DE PALAFOX y MENDOZA, Varon de deseos: en que se declaran las tres vias de la vida espiritual: purgatiua, iluminatiua y vnitiua].

- [23] 1. Yten, otro libro de a quartilla de la Vida de la madre Antigua [Andrés DE SAN AgUSTÍN, Vida exemplar, admirables virtudes y muerte prodigiosa de la $V$. Madre... Soror Maria de la Antigua, donada... de el Convento de Santa Clara del Orden de San Francisco en... Marchena, y... monja en el de la Mercenarias Descalcas de la Villa de Lora... ; con los Romances y versos que ... compuso... dicha V. Madre...].

- [24] 1. Yten, otro libro de a quartilla de la Vida de San Nicolás de Bari [Alonso de ANDRADE, Vida y milagros de San Nicolas el Magno..., patron de la ciudad de Bari]. 
- [25] 1. Yten, otro libro de a quartilla, Vida de Santo Thomás de Villaueua [Miquel Bartolomé SALOM, Vida y milagros del ilustrissimo... Tomas de Villanueva arcobispo de Valencia, del Orden de San Agustin].

- [26-28] 3. Yten, tres libros de a quartilla de Molina de oración [, Antonio DE MOLINA, Exercicios espirituales de las excelencias, prouecho y necessidades de la oracion mental: reducidas a doctrina y meditaciones: sacadas de los Santos Padres y Doctores de la Iglesia].

- [29] 1. Yten, otro libro de a quartilla intitulado la Mujer fuerte [Miguel GONZÁLEZ VAQUeRO, La Mujer fuerte, por otro titulo La vida de D. Maria Vela, monja de S. Bernardo en el convento de Santa Ana de Avila].

- [30]1. Yten, otro libro de quarto Práctica del catesismo romano y doctrina christiana, del padre Eusebio de Núremberg [Juan Eusebio NieremberG, Practica del catecismo romano y doctrina christiana: sacada... de los catecismos de Pio V y Clemente VIII...: con las divisiones y adiciones necessarias al cumplimiento de las obligaciones christianas...: van al fin añadidos varios exemplos de los puntos principales de la doctrina...].

- [31] 1. Yten, otro libro de a quartilla Vida y virtudes del benerable siervo de Dios Christóbal de Santa Cathalina, fundador del Hospital de Iesús Nazareno de Córdoua [Probablemente, Reglas y Constituciones que han de guardar los Hermanos del Orden Tercero del... Padre San Francisco, que asisten en la Cassa, y Hospital de Jesus Nazareno de... Cordoba... que fundo el... Padre Christoual de Santa Cathalina].

- [32] 1. Yten, un libro de a quartilla de las obras de la madre Ágreda [Posiblemente, María Jesús DE ÁGREDA, Mystica ciudad de Dios, milagro de su omnipotencia y abysmo de la gracia: historia divina y vida de la Virgen, Madre de Dios, Reyna y Señora nuestra Maria Santissima].

- [33] 1. Yten, otro libro de a quartilla Vida del padre maestro Luis de la Puente [Francisco CAHUPín, Vida y virtudes del venerable padre Luis de la Puente de la Compañia de Iesus...].

- [34] 1. Yten, otro libro de a quartilla Peregrinazión de Filotea al santo themplo y monte de la Cruz [Juan De Palafox y MendozA, Peregrinacion de Pbilotea al Santo Templo, y Monte de la Crui].

- [35] 1. Yten, otro libro de a quartilla intitulado Consuelo de pobres y remedio de ricos [de Matías DE AGUIRRE DEL POZO Y FELICES]

- [36] 1. Yten, otro libro de a quartilla del padre maestro Dáuila, intitulado de Audie fidia Juan DE ÁVILA, Libro espiritual sobre el verso, audi filia, que trata de como hemos de oyr a Dios, y huyr de los malos lenguajes del Mundo, Carne, y Demonio].

- [37] 1. Yten, otro libro de a quartilla de la Vida de San Francisco Javier [Francisco GARCía, Vida y milagros de S. Francisco Xavier, de la Compañia de Jesus, apostol de las Indias].

- [38]1. Yten, otro libro de a quarto Triunfo del agua bendita [del prior del Monasterio de Santa María de la Cuevas de Sevilla José DE SANTA MARía, impreso en Sevilla por Juan Fajardo en 1642].

Titivillus, ISSN 2387-0915, ISSN-e 2603-9966, 2 (2016), pp. 157-178 
- [39-40] 2. Yten, segunda y tercera en dos libros de a quartilla de las obras del padre Alonso Rodríguez, de la Compañía de Iesús [Posiblemente, Alonso RODRÍGUEZ, Exercicio de perfeccion y virtudes christianas...].

- [41] 1.Yten, otro libro de a quartilla Peregrinazión de Philotea al santo templo y monte de la Cruz [uan DE PALAFox y Mendoza, Peregrinacion de Philotea al Santo Templo, y Monte de la Crupl.

- [42] 1. Yten, otro libro de a quartilla de la Vida de Santa Rosa Viterbo [Alonso DE GuZmán, Compendio de la maravillosa Vida, Muerte, Reliquias y Milagros de Santa Rosa de Viterbo del tercero horden de S. Francisco...].

- [43] 1. Yten, otro libro de a quarta de la Vida y trauajos del padre fray Guillermo Grazián de la Madre de Dios, religioso carmelita [Andrés DEL MÁrmol, Excelencias, vida y trabaios del Padre Fray Geronimo Gracian de la Madre de Dios Carmelita: recopilada de la que escrivio del Santa Teresa de Iesus y otras personas] - [44]1. Yten, otro libro de a quartilla de la Vida de don Miguel Mañara Jjuan DE CÁRDENAS, Brene relacion de la muerte, vida y virtudes del venerable cauallero D. Miguel Mañara Vicentelo de Leca...].

- [45]1. Yten, otro libro de a quartilla intitulado Suma y compendio de los grados de oración [i.e. Suma y compendio de los grados de oracion: por donde sube un alma a la perfecion de la contemplacion] de la madre Santa Theresa de Iesús».48

${ }^{48}$ ADPSE. Hospital del Pozo Santo, Sec. Fundación y gobierno, leg. 1, s.f. 


\section{Figuras}

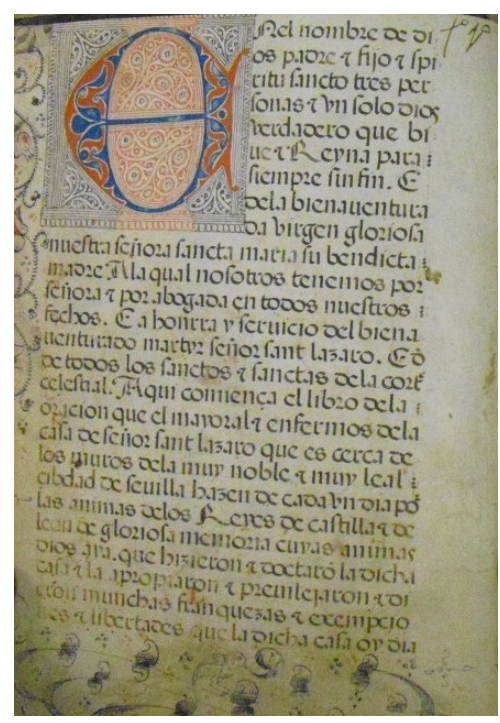

Fig. 1

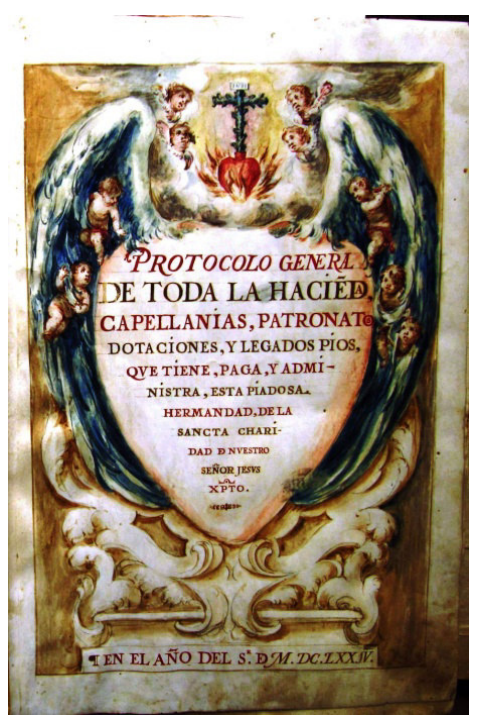

Fig. 3 Protocolo de la Caridad, 1674

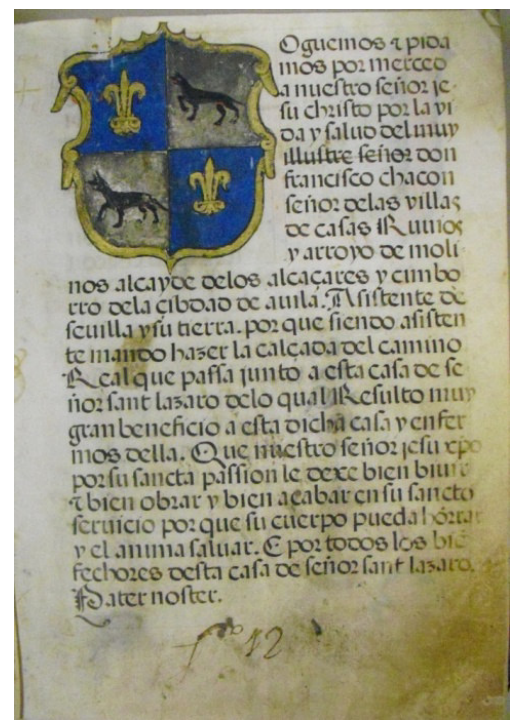

Fig. 2

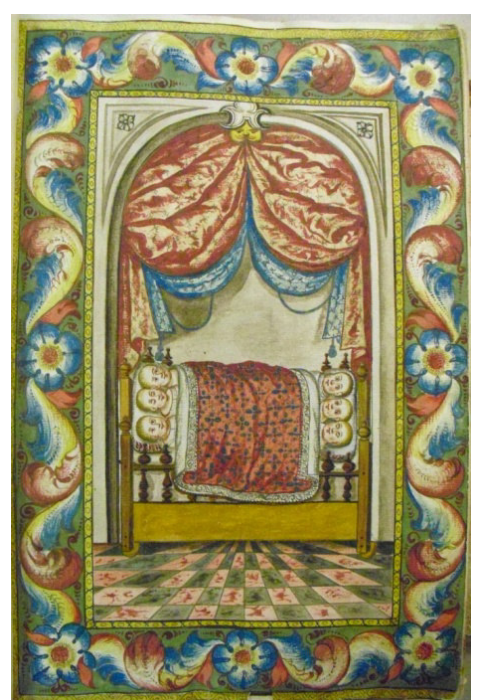

Fig. 4 Protocolo de la Casa Cuna, 1699 